
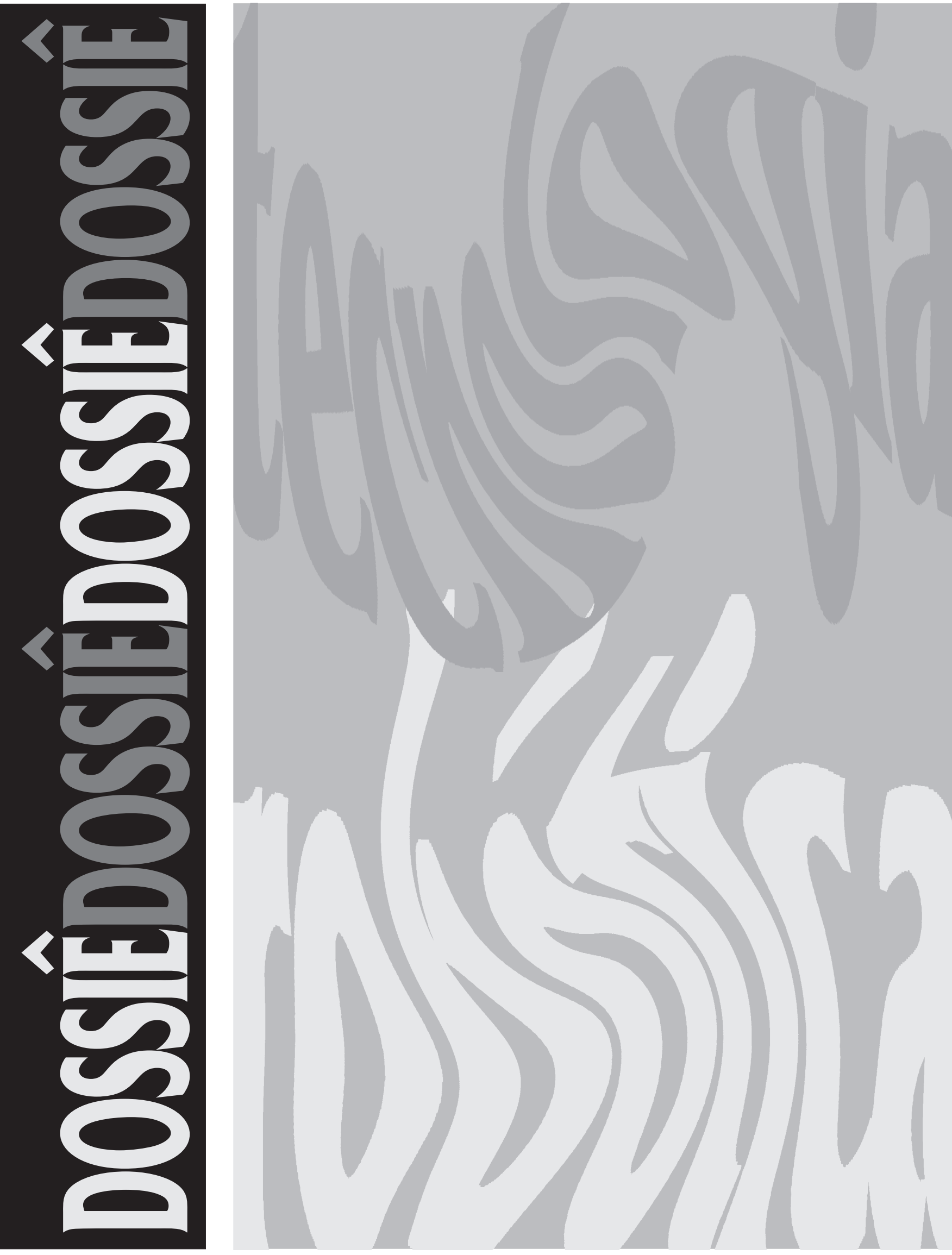


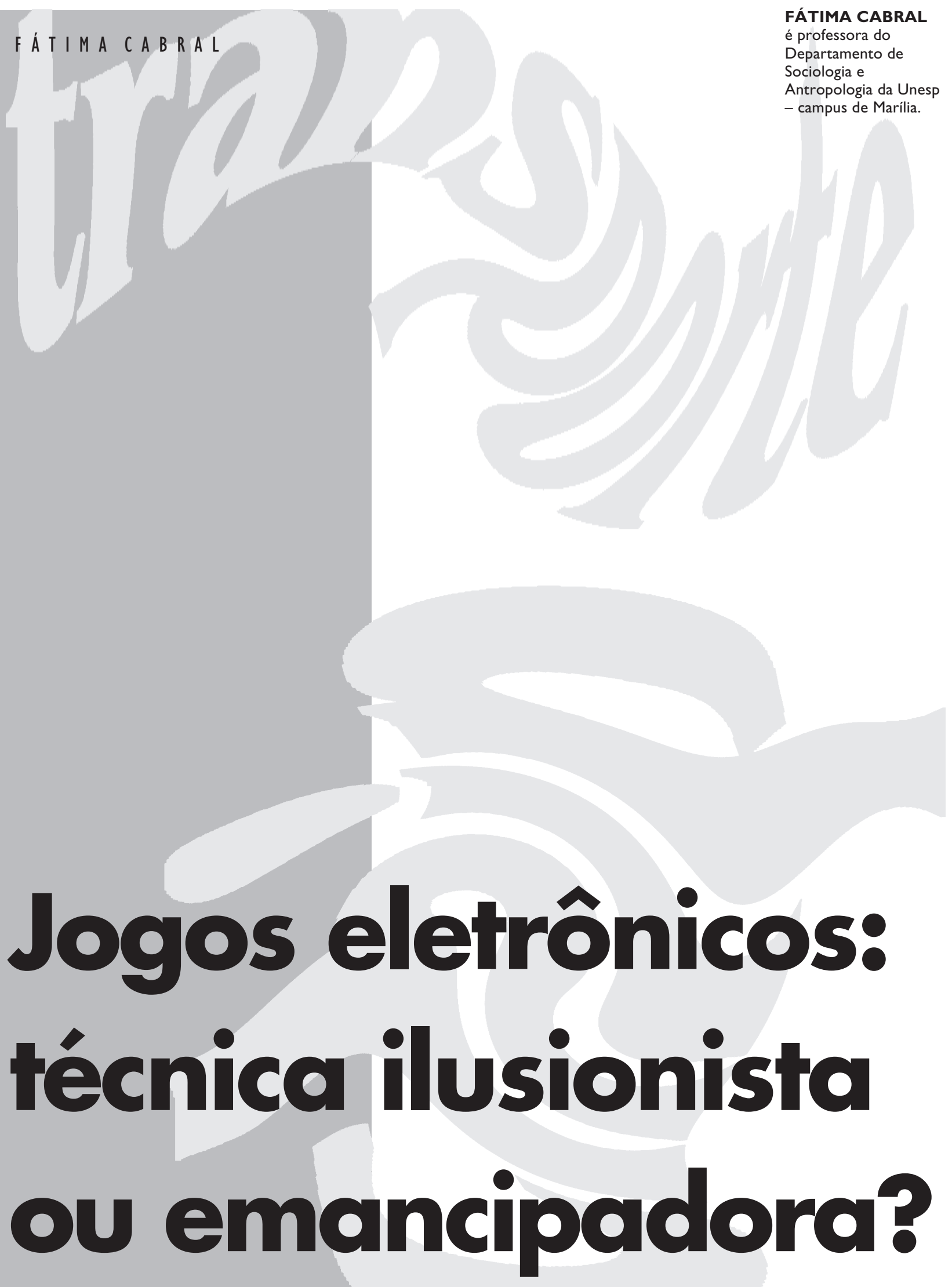

FÁTIMA CABRAL

Sociologia e

Antropologia da Unesp

- campus de Marília. 


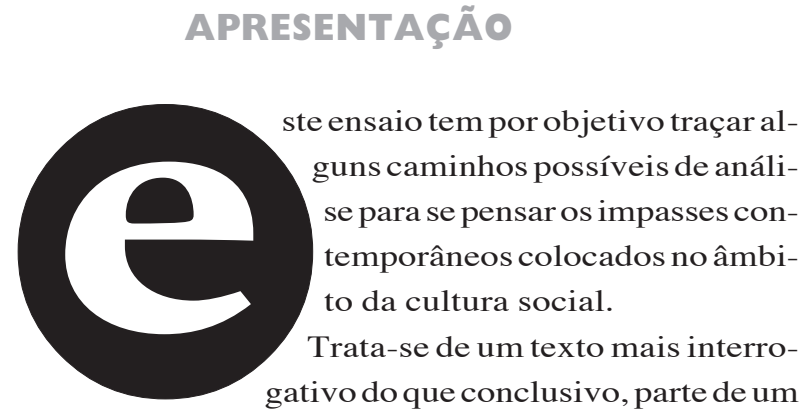
estudo mais amplo (1) em que se pretende verificar qual é a tendência cultural das atividades lúdicas em face da tecnologia: emancipadora ou massificadora? Em outros termos, busca-se compreender o lugar e o papel da cultura lúdica em um mundo cada vez mais automatizado, marcado pelo encurtamento da jornada de trabalho e pelo aumento do tempo livre.

$\mathrm{Na}$ atualidade, grande parte de nossas ações e relações é mediada por objetos eletrônicos. O desenvolvimento da indústria e a conseqüente divisão social do trabalho nos séculos XVII e XVIII apenas marcam o início das transformações que, em nossos dias, ganham uma sofisticação técnica inimaginável para aquele período.

Desde um simples transistor até o mais sofisticado chip testemunha-se o empenho do homem, ao longo do tempo, no sentido de aprimorar as diversas formas de comunicação. A rede informacional hoje potencialmente disponível coroa de êxito esse esforço.

A mecanização e a robótica, através dos seus mecanismos “inteligentes”, tornaram algumas máquinas aptas a exercer diferentes funções e a realizar complexas tarefas a partir de um simples gesto humano. O homem pode, assim, poupar muito de seu tempo, de sua força e de sua energia física pois em ambos os processos sua relação com o mundo objetivado tem-se reduzido principalmente às extremidades do seu corpo: pé, mão, olho.

Também o ritmo imposto pelo desen-

Referimo-nos à pesquisa que desenvolvemos como tese de doutoramento na USP.

2 "O homem de hoje não cultiva o que não pode ser abreviado" (Valéry, apud Benjamin, 1985, p. 206) estão tendo que aprender a encurtar sua fase infans. De modo especial, elas se iniciam nessa aventura tecnológica via jogos eletrônicos.

Esses jogos representam, para a cultura lúdica infantil - mas não só -, o que há de mais moderno e inovador em matéria de diversãoeletrônica. Também aparentam ser a expressão cultural do processo de mundialização que, emúltima instância, “cohabita e se alimenta" das culturas e dos imaginários locais e regionais (cf. Ortiz, 1994).

Tomados a partir desse duplo aspectosímbolo de modernidade e expressão da cultura global -, os jogos eletrônicos representam, em nosso estudo, uma estratégia de análise privilegiada.

Expressão mais bem acabada da cultura lúdica na modernidade, os jogos eletrônicos são mediadores entre a criança e os valores socioculturais que, sob determinado ponto de vista, se pretendem "globais". Enquanto globais, porém, os valores devem ser abstratos, desterritorializados, desenraizados, a fim de que possam ser alienáveis em todas as esferas da sociedade.

$\mathrm{Na}$ esfera da cultura lúdica, esses jogos parecem ser os que melhor sintetizam os valores universais. Nesse sentido, nosso objeto de estudo não se fecha nos jogos eletrônicos. Antes, abre-se com eles para tentar reconhecer, no âmbito da assim chamada pós-modernidade, as estratégias que possivelmente reforçam, ou que garantem, para as novas gerações, a absorção dos ideários fundantes da subjetividade social globalizada.

Trata-se, pois, de um estudo teórico sobre as possibilidades de realização, no âmbito da cultura, das bases ontológicas de um novo ser social que deverá buscar, para além do consumo padrão, a expressão omnilateral de si.

\section{TRABALHO E LAZER}

Diferente do que acontece às crianças, o adulto, quando joga ou brinca, realiza uma "fuga da realidade", uma fuga dos dias estafantes. Nesse sentido, as atividades 
lúdicas são apreendidas como uma resposta à necessidade básica que toda pessoa tem de relaxamento e distensão. Tais atividades tanto podem corresponder a um conceito psicológico de catarse, como a uma práxis habitual da sociedade moderna, onde o tempo é individualmente percebido como tempo de trabalho e tempo de lazer.

No âmbito da sociedade moderna, como assinalado por Marx nos Manuscritos de 1844, há um movimento contínuo de decomposição do processo produtivo, cuja conseqüência imediata é a formação de trabalhadores decompostos, desefetivados, na medida em que seu saber, antes objetivado na "matéria natural" pela sua ação concreta, teleológica, degradou-se ao se transformar, pela lógica do capital, em trabalho abstrato.

Dessa transformação - de trabalho concreto para trabalho abstrato - também resulta que as oportunidades de realização do homem no e pelo trabalho estão corrompidas pois aquele não mais se reconhece enquanto ser social, produtor de bens sociais, mas vê-se apenas como ser individual que se relaciona, de forma exteriorizada e fragmentária, com outros homens e com o produto dessa relação: o mundo das coisas estranhas e úteis. A esse fenômeno Marx chamou "estranhamento".

Assim, sob a divisão social do trabalho e sua forma mais acabada, a alienação do trabalhador na esfera produtiva, a possibilidade de realização omnilateral do indivíduo enquanto ser social, ou seja, a possibilidade de experimentar uma "vida plena de sentido", parece ter-se transferido, privilegiadamente, para a esfera do não-trabalho, esfera de um tempo tido como secundário. A ética do trabalho transformou-se, pois, em ética do consumo. Eé nesse âmbito que em um primeiro momento parece localizar-se, para o sujeito estranhado, a possibilidade de experimentação de uma atividade humanamente mais satisfatória.

Desse modo, para se contrapor ao mundo do trabalho, ao mundo das atividades mais graves, as atividades lúdicas, particularmente as infantis, permanecem envolvidas em uma espécie de "aura de inocência" e de desinteresse para o mundo adulto sugerindo, ainda, uma evasão, um intervalo na vida real.

Acontece que a vida cotidiana, como bem analisa Agnes Heller (1992), é heterogênea e no seu interior não podemos manter em reflexão, simultaneamente, todas as nossas capacidades ou atividades. Quanto mais profundamente nos entregamos a uma atividade - seja ela qual for: jogo, trabalho, o aprendizado de uma nova língua, etc. -, esse mergulho significa a "suspensão" das demais sem, contudo, perder o caráter orgânico com a vida ordinária.

A necessidade e a motivação é que determinarão a rotatividade de cada atividade hierarquicamente organizada no dia-adia. Em outros termos, a necessidade e a motivação determinarão qual ou quais atividades ficarão "suspensas", "desaparecerão”, e qual ou quais receberão de nós toda a concentração. Como se vê, essa faculdade de nos "transportar" para além do imediato é uma característica que encontramos não só no jogo, mas em toda e qualquer atividade à qual nos dedicamos com certo abandono, seja ela lúdica ou não.

Como brincar ou jogar são atividades costumeiramente atribuídas às crianças aquelas que, por um privilégio de classe, não necessitam dividir hierarquicamente esse tempo lúdico com o tempo de trabalho produtivo, parecem permanentemente envoltas em um círculo mágico, à mercê do seu encanto e ilusão. Todavia, antes mesmo de se constituir em entretenimento, o jogo ou a brincadeira têm, para qualquer criança, um valor cultural (ainda que disso ela não tenha consciência) construído a partir do mundo que a rodeia e do qual retira o conteúdo dessas atividades. Assim compreendidos, o brincar e o jogar infantil não podem ser considerados como um simples passatempo. Representam, antes, uma atitude lúdica criadora e socializante, pois transportam as crianças para diversas experiências, abrindo-lhes as portas para o entendimento da realidade e ajudando-as a construir suas próprias categorias axiológicas. 
3 Ver Antunes (1995), particularmente "Trabalho e Estranhamento", pp. 121-34

4 Como afirmam os apologistas da técnica - Bill Gates em particular -, todo processo tecnológico e informaciona objetiva simplificar humanizar a relação homem máquina. A respeito da estrada do futuro, B. G. promete: "Ela vai permitir capacidade que parecem mágicas quando descritas, mas que representam a tecnologia em ação para fazer nossas vidas mais fáceis e melhores. [...] A estrada da informação vai dar sensação de que todas as máquinas intermediárias entre você e o objeto de seu interesse foram removidas. Você indica o que quer e pronto! Na hora!" (Gates, 1995, pp. 90-I, grifos nossos). Sobre a "tendência humana" antropomorfizar as coisas ele tranqüiliza: "Algumas pessoas, ao ouvir falar de software interface social, acham horripilante a idéia de um computador humanizado. Mas acredito que mesmo essas pessoas vão acabar gostando dele, quando experimentarem. [..] Em programas como o Bob, da Microsoft, eles [pesquisadores] demonstraram que as pessoas tratarão os agentes mecânicos que têm personalidade com um grau surpreendente de consideração" (idem, pp. 1 13-4).

5 Joffre Dumazedier, em entrevista publicada na revista Sciences Humaines, no 44, novembro de 1994, pp. 36-9. Ver, do mesmo autor, A Revolução Social do Tempo Livre. Sobre o mesmo assunto, ver, ainda, Gorz (1982), Offe (1989) e particularmente Antunes (1995).
A partir desse ponto de vista sociocultural é possível perceber que, longe do aspecto que poderia caracterizar inocência, desinteresse, os jogos, assim como alguns elementos que lhes servem de suporte e algumas brincadeiras, têm um sentido claro de preparação para a vida adulta.

No caso mais específico do objeto deste estudo - os jogos eletrônicos -, busca-se analisar até que ponto eles cumprem esse papel ao ajudar as crianças a se adaptarem às mudanças tecnológicas. Todavia, até que ponto adaptar-se à tecnologia, em si, significa tornar-se mais apto ao futuro?

Não restam dúvidas quanto ao fato de as inovações tecnológicas exigirem um certo saber especializado, bem como o desenvolvimento de determinadas capacidades intelectivas e mesmo motoras. O que não é tão evidente, porém, é se esse desenvolvimento técnico far-se-á ou não acompanhar de um “desenvolvimento da personalidade humana" (3).

Em um universo cada vez mais automatizado, onde em tese desaparece o homo faber para dar lugar ao homo communicans, onde estão reduzidas as noções de transformação, de processo, de mudança, de criação e, no que diz respeito aos saberes, a qualificação do indivíduo, quais as "novas" virtudes e habilidades requeridas por um mercado cada vez mais ajustado pela técnica e gerador de uma mais rígida segmentação e dessencialização do trabalhador?

Por outro lado, com o emprego cada vez maior da tecnologia em todos os setores, o homem terá mais tempo livre para a elaboração e a fruição da cultura. Não obstante, é preciso indagar: $1^{\circ}$ ) de que tipo de cultura estamos falando ou deveremos falar; 2o) o que significa a "simplificação" trazida pela técnica a todos os processos da vida coletiva (4), e se esta simplificação, juntamente com a cultura de massa, a cultura do espetáculo, poderá obstaculizar e corromper ainda mais a "virtude intelectual" dos indivíduos, dificultando-lhes a possibilidade de, nesse tempo livre, desenvolver uma condição crítica para além do consumo padrão.
Dumazedier, considerado o pioneiro da sociologia do lazer, reconhece que "a passagem do tempo livre ao tempo de lazer não é só uma questão de números de horas livres, mas supõe, sobretudo, um espírito novo, em que o sujeito deverá usar o tempo livre para a realização de si e para a participação social" (5). Nesse sentido, nossas indagações anteriores podem também ser colocadas de outro modo: por estarem os sujeitos expostos desde a infância ao simulacro, eles terão melhores condições para buscar, nesse tempo livre, envolver-se em um processo de autoformação, tornandose sujeitos mais livres, independentes das influências condicionantes? Enfim, tornarse-ão sujeitos que, conhecendo bem a "arte ilusionista", compreenderão melhor as diferenças entre arte e técnicas audiovisuais, entre ciência, pseudociência e mídia, entre o real concreto e a realidade virtual, entre o imaginário do jogo e o imaginário social?

Se, como dissemos anteriormente, na sociedade moderna a possibilidade de realização do indivíduo foi transferida - ao menos aparentemente - para fora do processo produtivo, faz-se necessário uma investigação na esfera do não-trabalho para verificar as reais oportunidades de autorealização e de emancipação humana no tempo-de-não-trabalho, no tempo-livre.

Retirar a "aura de inocência" que protege a esfera do lazer adulto e as atividade lúdicas infantis representa, pois, desnudar os mecanismos ideológicos que obstaculizam a possibilidade de emancipação do ser social para além da esfera produtiva. Contudo, tomar como dialética a relação entre tempo de trabalho e tempo de lazer significa analisar os mecanismos ideológicos e de estranhamento a que estão submetidos os indivíduos em todas as esferas da vida social sob a égide do capital. E tal exercício impõe uma outra indagação ainda mais fundamental, síntese das anteriores: qual ou quais as oportunidades de se conquistar um "novo espírito" em uma sociedade que não promoveu, ainda, uma ruptura estrutural suficientemente capaz de permitir o desenvolvimento de uma nova ontologia? 


\section{A CULTURA DO ESPETÁCULO}

Acreditando que é especialmente pelo estudo das transformações históricas que se pode entender a diversidade, a variação e o papel dos jogos, assim como o conceito de tempo nas diferentes culturas, investigaremos a contribuição histórico-cultural dos jogos, particularmente na atualidade movida pela eletrônica, para tentar desvendar o que há de realmente "novo" e de "moderno" em comparação aos jogos chamados "tradicionais".

Os jogos eletrônicos aparentemente pairam acima das tradições culturais locais, na medida em que buscam uma padronização definida em escala global que parece pôr fim às antigas formas lúdicas de representação social e cultural; conservam independência em relação à realidade possível, ou seja, é o lugar por excelência da virtuosidade técnica, do fantástico, onde espaço e tempo (reais) são categorias inessenciais. Traduzem, portanto, a desterritorialização das culturas lúdicas através de um processo que já conhecemos como fetichização.

Tudo isso representa, indubitavelmente, novidade que encanta e fascina. Todavia, essa novidade pode ser também considerada moderna? Segundo Octavio Paz (1974) a novidade, para ser moderna, precisa de duas cargas explosivas: ser negação do passado e ser afirmação de algo diferente, entendido esse como aquilo que se opõe aos gostos tradicionais - estranheza polêmica, oposição ativa.

O conteúdo de alguns jogos eletrônicos, por sua vez, não parece sugerir nenhum estranhamento, negação, crítica, nada de inesperado: cinderelas, torres, dragões e cavaleiros que se arriscam para salvar a princesa ou a sua própria honra; às vezes é necessário astúcia para desvendar enigmas ou, pura e simplesmente, indica regras de conduta e de comportamento. Tal conteúdo sugere, talvez, um testemunho histórico, só que este vem destituído do peso da tradição e do mistério. Através da combinação entre conteúdo (aparentemente tradicional) e forma (moderna), é possível, porém, observar a "reprodutibilidade técnica" dos temas tradicionais, irreverentemente atualizados (Benjamin).

$\mathrm{Na}$ verdade, tais jogos parecem oferecer àqueles que os manipulam a possibilidade de se inserirem em uma "realidade" mais rica de emoção do que aquela que poderiam encontrar em suas próprias experiências, particularmente quando estas não correspondem às suas potencialidades criadoras. Enquanto a realidade é muitas vezes tomada como ilegítima, no jogo o que importa é a fantasia vivida eletronicamente. Assim sendo, os videojogos, principalmente os que sugerem violência, possivelmente funcionam como uma espécie de catarse para a angústia, o sonho, e também para a inclinação que jovens e crianças têm pelo perigo, pelo desafio competitivo, pela experiência.

E, nesse sentido, os videojogos parecem possibilitar uma inserção cultural, ainda que virtual, não muito diferente das experiências vividas com os jogos "tradicionais" e com as antigas competições, que em nosso estudo estarão incluídas na mesma categoria do jogo.

$\mathrm{Na}$ maioria das vezes, as competições aconteciam exatamente para demonstrar a superioridade dos homens, de grupos, de comunidades ou de países. Impulsionados pelo imperativo da honra, da fidelidade ou justa causa, sua relação com a cultura era objetiva e seu resultado notadamente importante para o grupo.

Todavia, ainda que os jogos eletrônicos repitam temas épicos - em uma sociedade que decretou a morte da epopéia -, o imperativo a que se obedece ao manipulá-los é o da exaltação do ego. Sua relação com a cultura, porém, não deixa de ser também objetiva, na medida em que é esse o sintoma encorajado pela cultura narcísica onde se movem esses sujeitos.

Como acentuado no início consideramos que jogos, brinquedos e brincadeiras de uma maneira geral atuam como educadores de atitudes. Pretendemos ressaltar, 
com isso, que o mundo dos jogos e das brincadeiras não está situado apenas no mundo do fantástico, do ilusório. O brincar ou o jogar são, antes, facetas de uma atividade arbitrária e objetiva; representam um mergulho na cotidianidade vivida mais do que um divertimento evasivo ou desinteressado. Assim, longe de constituírem um objeto menor para a análise sociológica, os jogos podem ser elementos reveladores da degeneração ou da emancipação da cultura em determinado momento histórico. Isso significa que tomamos os jogos como substância da sociedade, a ponto de, direta ou indiretamente, influírem no destino das culturas.

No que diz respeito aos jogos na era da eletrônica - marca indelével da sociedade contemporânea -, é possível ver também ali mais uma vez representada a contradição própria do mundo moderno: a esclerose do saber frente à sofisticação tecnológica.

Em trabalho anterior (6) procuramos chamar a atenção sobre o papel e a importância dos jogos, dos brinquedos e das brincadeiras no processo de socialização infantil. Analisando trinta relatos sobre a experiência lúdica de pessoas que viveram a infância entre 1930 e 1980, pudemos perceber uma certa diluição, ao longo do período, das brincadeiras livres, em função especialmente do desaparecimento de espaços adequados à sua prática (tais como quintais e terrenos baldios), bem como a substituição de determinados brinquedos que antes eram criados e confeccionados pelas próprias crianças por brinquedos industrializados que representam, não raro, uma réplica perfeita, miniaturada, de objetos do mundo adulto (7).

A cada subespaço tratado - rural, urbano, quintal, rua - corresponde um tempo diferente. No espaço rural - passado mais remoto - detectamos uma relação determinante de vizinhança e consangüinidade. Esse espaço era, pois, um lugar de iguais. Quanto à cidade, pelo menos até a década de 1960, aproximadamente, é também possível, nessa pesquisa, concebê-la como um espaço mais ou menos homogêneo, onde o quintal e a rua eram quase que

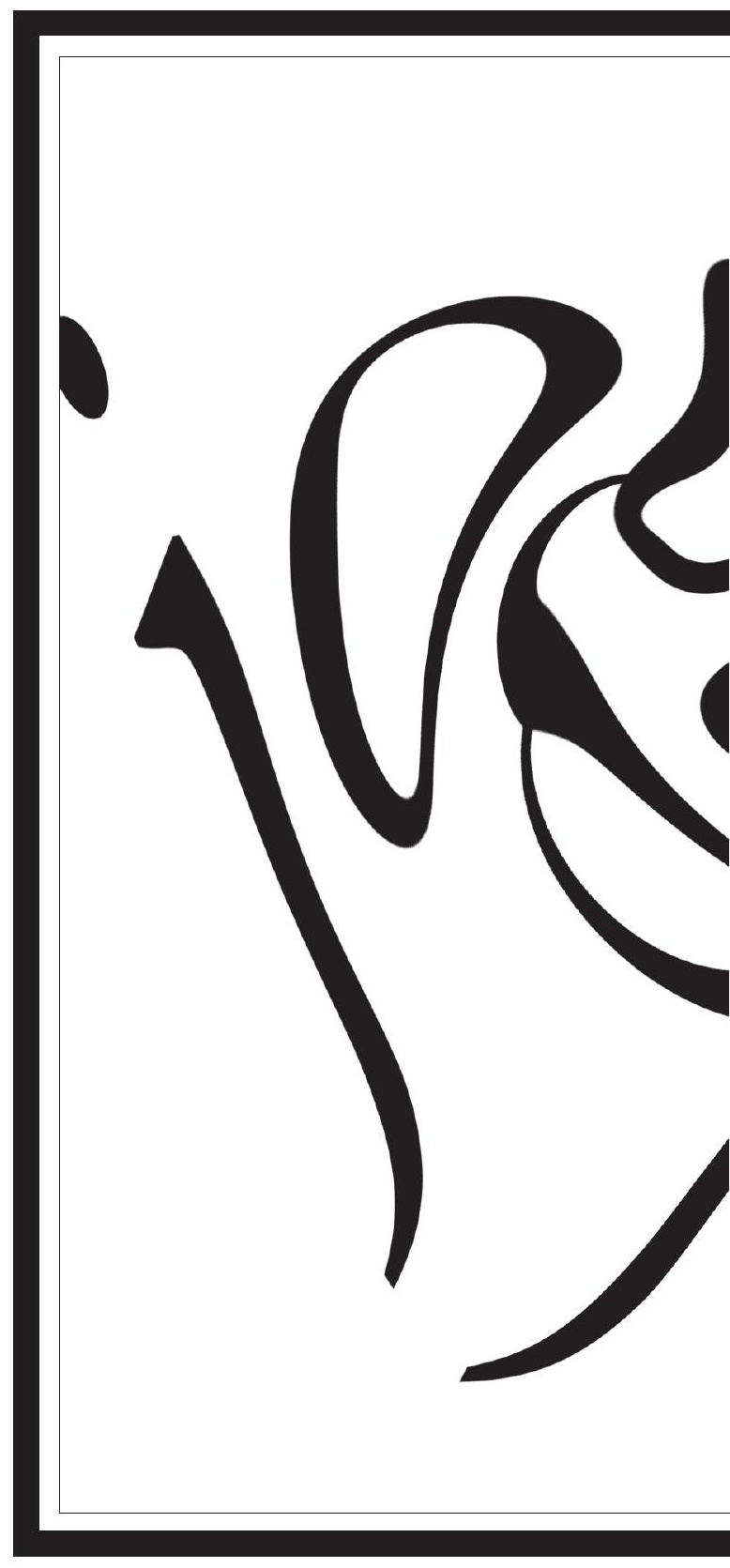

uma extensão da casa. As transformações urbanas, entretanto, diferenciaram cada vez mais esses subespaços, assinalando fortemente os limites entre o público e o privado quando, então, a discussão sobre o ordinário da vida passa por outros determinantes - relações impessoais e espaços diferenciados, por exemplo.

Assim, até aproximadamente a década de 1960, a conceitualização de tempo e espaço estava determinada mais pelo aspecto qualitativo das relações - sociais e de produção - em uma espécie de aliança en- 


$$
\text { of }
$$


8 "Não uma destruição qualquer, da negação do todo, indistintamente, mas uma destruição consciente, planejada, pensada, na qual se escolhe 0 que se pretende preservar, a que se pretende chegare, po conseqüência, o que se pretende acabar. Não há construção nova sem esse tipo de destruição: rompe-se a pedra e constrói-se o dique; tira-se barro, faz-se o tijolo; corta-se a lã e o tecido, monta-se roupa: tritura-se o trigo, faz-se o pão" (Lima, 1989, pp. 80-I)

9 Em nossa época, paralelo à esclerose de determinados saberes, assiste-se ao ocaso daquilo que é "obra da inteira história universal: a educação dos cinco sentidos". K. Marx, Mc nuscritos Econômico-Filosóficos.

10 Talvez seja oportuno retomar aqui o alerta de A. Smith ao analisar os efeitos da industrialização e da conseqüent mecanização no século XVIII: "A uniformidade de sua vida estacionária corrompe naturalmente também a coragem de sua mente. [...] Ela destró mesmo a energia de seu corpo e o incapacita a emprega suas forças com vigor e perseverança, a não ser na operação parcial para a qual foi adestrado. Sua habilidade em seu ofício particular parece assim ter sido adquirida custa de suas virtudes intelectuais, sociais e guerreiras" (A. Smith, apud Marx "Divisão do Trabalho e Manufatura", p. 284)

I I Nossa pesquisa de mestrado também aponta, no que diz respeito aos jogos eletrônicos, que estes parecem marcar, de forma inequívoca, o fim de um tempo em que se podia detec tar, em cidades grandes e médias, uma cultura regional, um estilo de vida local, especialmente no que tange à troca de experiências, aos gestos signifcativos, ao contato dos corpos nos momentos épicos da infância: "as experiências estão deixando de sercomunicáveis" e "o valor de certas afinidades singulares entre a alma, o olho a mão" não mais transparece nas relações. $O$ saber contido na tradição se desvanece: não há o que ser cambiado, ensinado (Benjamin, p. 1985). O sistema de informação (computadorizado, tecnificado), eixo central no processo de "mundialização da cultura", parece pois, exacerbar o que já previra o pensador: estamos cada vez "mais pobres em histórias surpreendentes" pois "tudo está a serviço da informação" em "evitar explicacões". lustrativo, nesse sentido, é o filme Denise Está Chamando. gem destinada a realizar um gesto particular" (Matos, s/d). A crescente produtividade nas cidades mina, pouco a pouco, aquela estrutura mais homogênea. $\mathrm{O}$ espaço passa a ser um espaço de desigualdades, de independência, provocando um processo de "desenraizamento" (Bosi, 1987) em que a tradição cultural, incluíndo aí o brincar, transforma-se cada vez mais em atividade-consumo (pelo tipo e quantidade de brinquedos). Com a industrialização, o brinquedo escapa "do controle da família, tornando-se cada vez mais estranho não só às crianças, como também aos pais" (Benjamin, 1985, p. 246).

Podemos, então, perceber que não é só através da divisão do processo de trabalho que se rompe a integração do homem com a natureza e com suas raízes. A reformulação do espaço social - em função também da tecnologia e seguindo, pois, os mesmos mecanismos do processo produtivo - se encarrega de apagar os vestígios, os signos que encontrariam eco em nossa memória. Portanto, o "desenraizamento" do sujeito nada mais é do que a destruição de todas as marcas, dos símbolos - materiais ou rituais - que constituem, com ele, o passado.

Através das brincadeiras tradicionais, as crianças aprendiam, quando misturadas às tintas, areia, ossos, palhas, madeira, etc., que a todo processo de construção está ligada a idéia de desconstrução, de transformação, de mudança destrutiva (8).

Já com os jogos eletrônicos as crianças parecem alienar-se em sua atividade lúdica e passam a empregar cada vez menos os seus sentidos (9) - exceto particularmente a visão: observam efeitos mirabolantes na tela, sem perceber que tais efeitos são o resultado de combinações numéricas matematicamente organizadas por um adulto (o programador). A interação da criança com o meio é mínima. E, logo após descobrir a seqüência lógica daquelas combinações, nada mais a surpreende, nem mesmo perceber que todos os seus conhecimentos estão reduzidos a um gesto: apertar o botão certo no espaço de tempo previamente programado (10).

Paradoxalmente, junto à infinidade de objetos e estímulos produzidos para consumo, da crescente liberdade de comunicação, verifica-se a diminuição das experiências cambiáveis e de conteúdos comunicáveis (11). A fruição dos objetos é cada vez mais alienada e esta alienação, por seu lado, vicia cada vez mais as faculdades humanas.

Frente a esse impasse, coloca-se a hipótese de que a tendência dos jogos eletrônicos é atuar, particularmente entre as crianças, como legitimador da lógica burguesa, na medida em que através deles consegue-se "educar" as pessoas, acostumando-as a interagir com a ordem, além de buscar uma melhor qualificação para o capital. Ou seja, o sistema de representação e de valores sociais atinge cada vez mais e o mais cedo possível o maior número de pessoas, podendo até torná-las aptas a decifrá-lo, mas quase nunca a questioná-lo.

Se houve um momento em que o apelo ao mercado consumidor da cultura de massa dirigia-se a uma faixa etária que variava mais ou menos dos 14 aos 60 anos, atualmente esse limite ampliou-se (12). Alcança a criança acelerando sua autonomia (13) em detrimento da infância, ao mesmo tempo em que infantiliza o adulto que passa a disputar com a criança a posse do videogame ou particularmente do computador que, desse modo, ora é instrumento de trabalho, ora é objeto de entretenimento.

Nesse sentido o computador, por um lado, aprofunda o recolhimento trazido pela televisão e, por outro, prenuncia aquilo que acontece de forma mais ampla na sociedade: o desaparecimento da divisão por faixa etária.

Essa ampla "geração eletrônica” tem, pois, que aprender a decifrar os códigos e sinais que lhe são apresentados pela "comunidade global”, ao mesmo tempo em que é frequientemente submetida a "testes de inteligência" para medir-lhe a ra- 


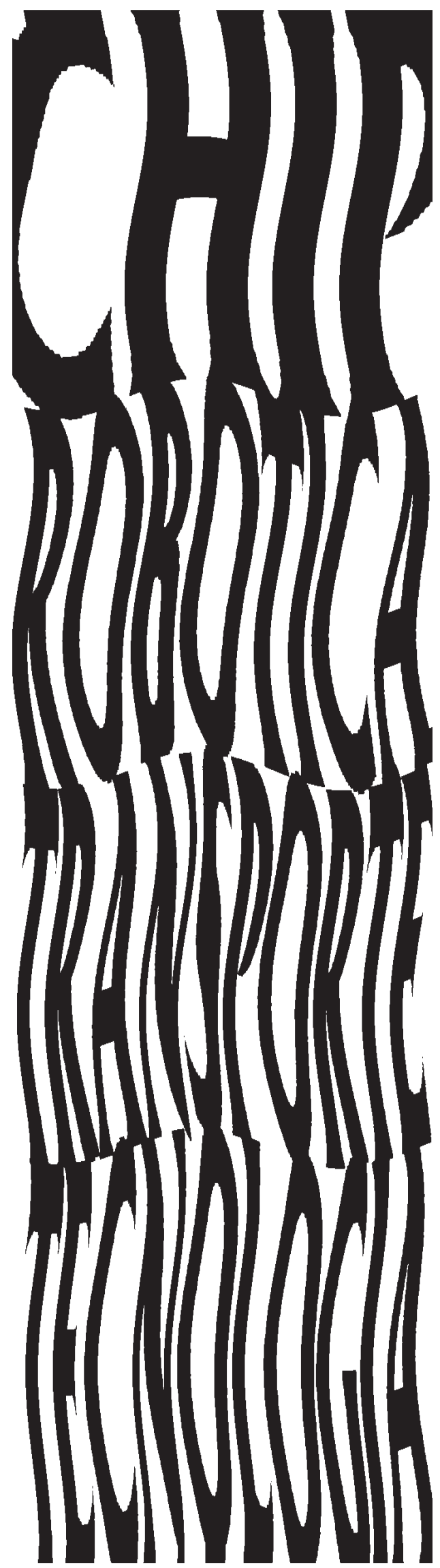

pidez de raciocínio. Esses testes de múltipla escolha servem para "medir" o conhecimento e a capacidade que o indivíduo tem de dar respostas imediatas, cronometradas, em que a elaboração do pensamento, a meditação, a ponderação, dão lugar, mais comumente, à indução. Exige-se, pois, nem tanto maturidade existencial, mas rapidez mental (14).

As novas tecnologias e as conseqüentes transformações socioestruturais, emocionais, de linguagem e de comportamento que elas impõem já às crianças e aos jovens parecem, pois, deslocar o conhecimento empírico em direção a um conhecimento mais abstrato e harmonioso, dando uma idéia de sociedade que pode ser ordenada por ajustes técnicos e pela manipulação de botões: basta encontrar a combinação adequada e tudo se ajusta na medida exata.

Atualmente, paralelo às possibilidades de desenvolvimento das habilidades motoras e intelectivas, esses jogos ajudam o indivíduo a interagir mais rapidamente com o establishment cultural e social. Basta lembrarmos que o conteúdo dos jogos eletrônicos é tecnicamente controlado e que as "respostas", as "saídas”, devem ser buscadas por meio do processo de indução, ou seja, pela tentativa de erro e acerto, experimentando apenas as possibilidades que o jogo oferece. Parece, pois, tratar-se de uma versão nova, e mais eficaz no que diz respeito à razão utilitária, do modelo de jogo idealizado por Platão (15). Trata-se, na verdade, de um jogo que lembra a todo momento a ineficácia de se buscar saídas alternativas para além do "possível”, pois no seu âmago triunfa a regularidade, a identidade, a norma.

Não obstante, a superação dessa racionalidade adequada ao capital deve ainda ser buscada na cultura - mas de sentido completamente diferente da cultura de massa - e na estética enquanto projeto cultural que desmascara a superficialidade da espetacular cultura pós-moderna, e entabula a relação dos homens com o futuro.

12 Em função do aumento da expectativa de vida dá-se mais atenção hoje à chamada 3a idade, principalmente sob o ponto de vista do consumo. Todavia, não é nossa intenção abordaressa faixa etária.

13 Para a criança, manipular objetos que fazem parte do "mundo adulto" é algo muito significativo. Primeiro porque ela está sempre aberta para experimentar algo novo, diferente; a criança tem pressa de se tornar adulto para poder fazer coisas que são vetadas ao "seu" mundo. Segundo: por ter um senso de desafio que supera o medo, a criança aprende, não raro, com muito mais rapidez e eficiência do que alguns adultos, a mexer em instrumentos eletrônicos, particularmente em computadores. Isso significa, sem dúvida, alcançar status e uma certa autonomia no seu mundo ainda infantil.

14 Vale a pena recorrer novamente a A. Smith: "A inteligência da maior parte dos homens, diz A. Smith, desenvolve-se necessariamente a partir e por meio de suas ocupações diárias. Um homem que despende toda a sua vida na execução de algumas operações simples [...] não tem nenhuma oportunidade de exercitar sua inteligência. [...] Ele torna-se geralmente tão estúpido e ignorante quanto é possível a uma criatura humana" (apud Marx, idem, ibidem).

I5 Platão só admitia liberdade plena das regras dos jogos para as crianças de até seis anos. A partir dessa idade as regras deveriam permanecer fixas e inalteradas, pois caso se habituassem às mudanças nas leis do jogo, os jovens desejariam experimentar mudanças também nas leis da cidade, o que, segundo ele, seria muito perigoso para a democracia ("Les Lois", VII). 


\section{BIBLIOGRAFIA}

ADORNO, T. W. Educação e Emancipação. São Paulo, Paz e Terra, 1995.

"Crítica Cultural e Sociedade"; "Teses sobre Sociologia da Arte”, in

Gabriel Cohn (org.), Adorno. São Paulo, Ática, 1994.

ANTUNES, Ricardo. Adeus ao Trabalho? Ensaio sobre as Metamorfoses e a Centralidade do Mundo do Trabalho. São Paulo, Cortez; Campinas, Editora da Universidade Estadual de Campinas, 1996. BAUDELAIRE, C. A Modernidade de Baudelaire. Rio de Janeiro, Paz e Terra, 1988. BENJAMIN, W. "A Obra de Arte na Era de sua Reprodutibilidade Técnica" e "O Narrador. Considerações sobre a Obra de Nikolai Leskov", in Obras Escolhidas. Magia e Técnica, Arte e Política. São Paulo, Brasiliense, 1985.

BOSI, Ecléa. Memória e Sociedade - Lembrança de Velhos. São Paulo, T. A. Queiroz, 1987. CABRAL, Fátima A. "O Lúdico no Interior Paulista: Processos de Mutação e seus Significados”. Dissertação de mestrado defendida em Araraquara, 1992.

DUMAZEDIER, Joffre. A Revolução Cultural do Tempo Livre. São Paulo, Nobel/Sesc, 1994. "Entrevista", in Sciences Humaines, no 44, novembro de 1994.

EAGLETON, Terry. "Capitalismo, Modernismo e Pós-modernismo", in Revista Crítica Marxista, vol. I, no 2, São Paulo, Brasiliense, 1995.

GATES, Bill. A Estrada do Futuro. São Paulo, Companhia das Letras, 1995.

GIDDENS, Anthony. As Conseqüências da Modernidade. São Paulo, Editora da Unesp, 1991.

GOLDMANN, Lucien. Dialética e Cultura. Rio de Janeiro, Paz e Terra, 1991.

GORZ, André. Adeus ao Proletariado (Para Além do Socialismo). Rio de Janeiro, Forense Universitária, 1982.

HARVEY, David. Condição Pós-Moderna. São Paulo, Loyola, 1992. . "Il Problema della Globalizzazione", in Marxismo Oggi. Rivista

Quadrimestrale di Cultura e Politica. Teti Editore - Milano. Anno IX - Nuova Serie n. 2, maggio-agosto, 1996.

HELLER, Agnes. O Cotidiano e a História. Rio de Janeiro, Paz e Terra, 1992.

HOBSBAWM, Eric. Era dos Extremos. O Breve Século XX - 19/4-199I. São Paulo, Companhia das Letras, 1995.

IANNI, Octavio. A Sociedade Global. Rio de Janeiro, Civilização Brasileira, 1992.

JAMESON, Fredric. "Reificação e Utopia na Cultura de Massa", in Revista Crítica Marxista, vol. I, no I, São Paulo, Brasiliense.

KURZ, Robert. O Colapso da Modernização. Rio de Janeiro, Paz e Terra, 1993. "Pós-modernidade e Sociedade de Consumo", in Novos Estudos Cebrap, no 12, jun/85.

LASCH, Christopher. A Cultura do Narcisismo. A Vida Americana numa Era de Esperanças em Declínio. Rio de Janeiro, Imago, 1983.

LESSA, Sérgio. Sociabilidade e Individuação. Maceió, Edufal, 1995. - A Ontologia de Lukács. Maceió, Edufal, 1996.

LIMA, Mayumi Souza. A Cidade e a Criança. São Paulo, Nobel, 1989. 
LOJKINE, Jean. A Revolução Informacional. São Paulo, Cortez, 1995.

LUKÁCS, G. "Introdução aos Estudos Estéticos de Marx e Engels", in Ensaios sobre Literatura. Rio de Janeiro, Civilização Brasileira, 1965.

El Asalto a la Razón. La Trayetória del Irracionalismo desde Schelling asta Hitler.

Barcelona/México, Grijalbo, 1972.

. Ontologia Dell'Essere Sociale. I, II, Roma, Riuniti, 1976.

"As Bases Ontológicas do Pensamento e da Atividade do Homem", in

Temas de Ciências Humanas. São Paulo, Ciências Humanas, no 4, 1978.

"Para uma Crítica Marxista da Sociologia", in José Paulo Netto (org.),

Lukács, São Paulo, Ática, 1981.

MARCUSE, H. L'Homme Unidimensionnel. Essai sur l'Idéologie de la Société Industrielle

Avancée. Paris, Minuit, 1968.

MARX, Karl. Manuscritos Econômico-Filosóficos (1844), in Os Pensadores. São Paulo, Abril

Cultural, 1978.

. "A Mercadoria"; "Divisão do Trabalho e Manufatura", in O Capital, vol. I.

São Paulo, Abril Cultural, 1983.

MARX E ENGELS. Sobre Literatura e Arte. São Paulo, Mandacaru, 1989.

MATOS, Olgária C. F. Os Arcanos do Inteiramente Outro. A Escola de Frankfurt, a Melancolia e a Revolução. São Paulo, Brasiliense, 1995.

. O lluminismo Visionário: Benjamin, Leitor de Descartes e Kant. São Paulo,

Brasiliense, 1993.

"A Cidade e o Tempo: Algumas Reflexões sobre a Função Social das

Lembranças”. Comunicação apresentada na 34a Reunião Anual da SBPC, Simpósio

"Cidade e Utopia".

MÉSZAROS, István. Marx: a Teoria da Alienação. Rio de Janeiro, Zahar, 198I.

- Produção Destrutiva e Estado Capitalista. São Paulo, Ensaio, 1996.

. O Poder da Ideologia. São Paulo, Ensaio, 1996.

OFFE, C. "Trabalho como Categoria Sociológica Fundamental?", in Trabalho \& Sociedade, v. I. Rio de Janeiro, Tempo Brasileiro, 1989.

ORTIZ, Renato. Mundialização e Cultura. São Paulo, Brasiliense, 1994.

PAZ, Octavio. "A Tradição da Ruptura" e "A Revolta do Futuro", in Os Filhos do Barro. Do Romantismo à Vanguarda. Rio de Janeiro, Nova Fronteira, 1984.

PELLEGRINI, Tânia. "Aspectos da Produção Cultural Brasileira Contemporânea”, in Revista Crítica Marxista, vol. I, no 2, São Paulo, Brasiliense, 1995.

PLATON. "Les Lois VII", in Oeuvres Complètes. Tome XII. Paris, Les Belles Lettres, 1956.

SANTOS, Boaventura de Sousa. Pela Mão de Alice. O Social e o Político na Pós-modernidade.

Porto, Edições Afrontamento, 1994.

SCHILLER, Friedrich. A Educação Estética do Homem. São Paulo, lluminuras, 1995.

SENNETT, Richard. O Declínio do Homem Público. As Tiranias da Intimidade. São Paulo,

Companhia das Letras, 1989. 